\title{
FROM WOOD TO CAREY TO MALLOCK: A REVIEW OF BILL CAREY'S WORK ASSOCIATED WITH THE MALLOCK-WOOD EQUATION AND THE ACOUSTICS OF BUBBLY LIQUIDS AND GAS-BEARING SEDIMENTS
}

\author{
Preston S. Wilson ${ }^{\mathrm{a}}$, Craig N. Dolder ${ }^{\mathrm{a}}$, Ronald A. Roy ${ }^{\mathrm{b}}$ and Allan D. Pierce ${ }^{\mathrm{b}}$ \\ ${ }^{a}$ Mech. Eng. Dept. and App. Res. Labs., The Univ. of Texas at Austin, Austin, TX, USA \\ ${ }^{\mathrm{b}}$ Dept. Mech. Eng., Boston University, Boston, MA, USA
}

Preston S. Wilson, The University of Texas at Austin, 1 University Station C2200, Austin, TX 78712; USA, email: pswilson@mail.utexas.edu, fax: +1-512-471-8727

\begin{abstract}
One of Bill Carey's many scientific interests throughout his career was the acoustics of bubbly liquids. Many underwater acousticians know of Carey's work associated with bubble clouds and more recently, gas-bearing sediments, but Bill got his start with the subject earlier in his career, studying flow in a boiling water reactor while employed at Argonne National Laboratory. Here, the acoustic velocity of bubbly liquid is of interest because of the possibility of supersonic flow, at comparatively low flow rates, in the high-void-fraction mixture within the reactor's piping system. In this talk, an overview of Bill's work with the acoustics of bubbly liquids will be presented, including noise and scattering from bubble clouds, and sound propagation within bubbly liquid and gas-bearing sediments. Finally, Bill's campaign to rename a famous equation (Wood's Equation) in honor of its forgotten originator (Mallock) will be reviewed. [Work supported by ONR.]
\end{abstract}

Keywords: bubbly liquids, ocean ambient noise, scattering, bubble clouds, gas-bearing sediments 


\section{ORIGIN OF CAREY'S INTEREST IN BUBBLY LIQUIDS}

A review of Bill Carey's earliest publications reveals that he was thinking about acoustic bubbles from the very beginning. His first two publications were related to the acoustic detection of bubbles associated with decompression sickness, and were written while Bill was still a student at Catholic University. [1,2] After obtaining his PhD, Bill's work centered around his training as a nuclear physicist when he was employed at Argonne National Laboratory (ANL) and was involved in nuclear reactor design and control instrumentation, but bubbles were still at the center of his activities. At ANL, Bill worked on topics related to the detection of boiling in reactor systems. [3, 4] It is interesting to note, that even at this early time in his career, Bill's work was already foreshadowing his later career. The first sentience of Ref. [3] reads "The objectives of this report are to discuss the detection, classification, and, possibly, the localization of boiling in a liquid metal fast breeder reactor by means of a few acoustic sensors positioned in the outlet plenum...," which was indeed referring to the sonar equation, discussed subsequently in the same report. Also discussed are the detection of signals in noise and the analysis of ambient noise.

Propagation in bubbly liquids was not discussed in Bill's early work, but while at ANL, Bill encountered research by Karplus [5] on sound propagation in bubbly liquid, which was conducted several years earlier at a neighboring institute in service of the design of boiling water reactors. The low sonic velocity found in high void fraction bubbly liquids flowing though piping in a boiling water reactor, leads to supersonic flow conditions at comparatively low flow rates, hence the interest in that field. This relatively obscure paper by Karplus, which was only published as a technical report, was later cited by Bill, and shared with colleagues and students many times in subsequent years, and became the basis of experimental work he conducted late in his career while a professor at Boston University. The Karplus paper may have also been one of Bill's earliest encounters with Wood's equation and the use of a one-dimensional acoustic resonator to determine sound speed. None-the-less, it is clear that Bill was thinking about sonar and underwater acoustics before he formally began working in the field.

\section{BUBBLE CLOUDS AND AMBIENT NOISE IN THE OCEAN}

We now fast-forward about ten years to the mid-1980s. Bill had been trying to understand the cause of a particular feature of ocean ambient noise: a rise in the lowfrequency noise spectrum associated with increased wind speed. At the Fall 1985 meeting of the Acoustical Society of America (ASA), Bill hypothesized that this noise was due to the collective oscillation of breaking-wave-generated subsurface bubble clouds. This material was presented during the meeting but did not appear in the published abstract. [6] (Aside: Bill himself always jointly credited Andrea Prosperetti with first presenting this hypotheses. Prosperetti also discussed collective bubble cloud oscillations in the same ASA meeting session. [7]) He then embarked on more than decade-long research journey to prove this hypothesis, which he (along with co-workers and other members of the ocean acoustics community) eventually did. The key idea was the following: wind-driven breaking waves generate bubble clouds under the spilling breaker. These bubble clouds radiate sound upon their generation that is responsible for the ambient noise feature previously mentioned. The sound radiation is driven by the collective volumetric 
oscillation of the cloud and is governed by the effective sound speed of the two-phase mixture that makes up the cloud and the overall size of the cloud. Wood's equation [8] relates the sound speed inside the cloud to the volume fraction of gas bubbles in the mixture and is independent of bubble size, since the collective oscillation frequency is well below the resonance frequency of largest single bubble. Moreover, the dimensions of the cloud are smaller that the wavelength of acoustic emissions. The cloud therefore behaves, to first order, as an effective fluid sphere, and given the low sound speed inside the cloud and typical oceanic bubble cloud dimensions, the frequency of this collective oscillation matches that of the observed ocean ambient noise measurements. Several publications described this work [9-14] and a typical result is shown in Fig. 1, which is the experimental apparatus and radiated noise spectrum from an artificial breaking wave event. [15] It was along this research path that Bill began extensive use of Wood's equation that continued throughout his career.
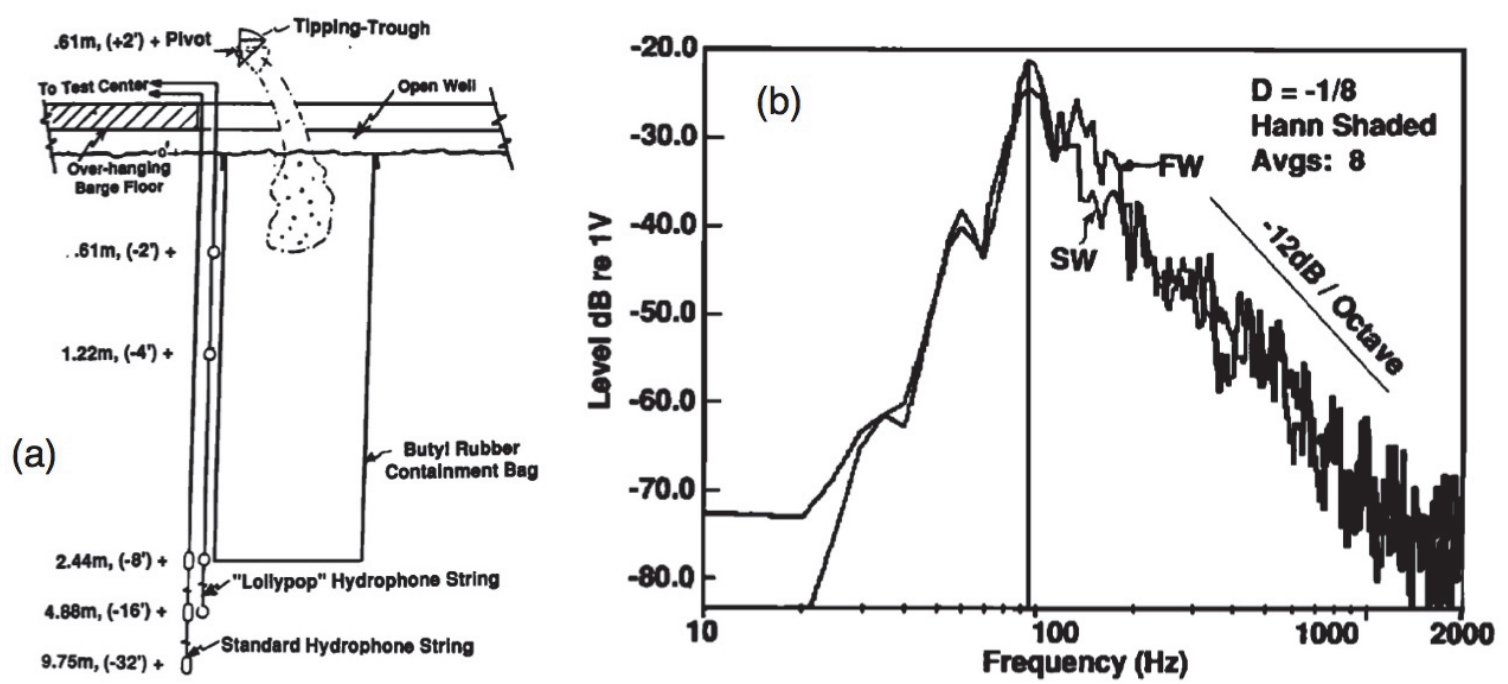

Fig.1: Tipping trough apparatus (a) used to generate model breaking waves and (b) radiated noise spectra from bubble clouds produced by model breaking waves in fresh and salt water. The peaks in the spectra are near $100 \mathrm{~Hz}$, showing that bubble clouds can indeed radiate low frequency noise. Figures adapted from Ref. [15].

\section{SCATTERING FROM BUBBLE CLOUDS}

If radiation of sound from an object is one side of a coin, then scattering of sound from that object is the other side. To further support the aforementioned hypothesis, Bill Carey sought to measure and model acoustic scattering from bubble clouds. One of these measurement campaigns became known as the Lake Seneca experiment. The experimental arrangement is shown in Fig. 2(a), and consisted of a source of compressed air that fed an air plenum and needle bank, used to make freely rising bubble clouds on demand at a depth of $91 \mathrm{~m}$ in a fresh water lake. The bubble cloud rose up in the water column and intersected the acoustic axis of a monostatic sonar system that was used to measure the rising cloud's target strength. A typical result is shown in Fig. 2(b), including measured target strength compared to a model prediction based on scattering from an effective fluid sphere, with acoustic properties derived from knowledge of the cloud's void fraction and Wood's equation. [16] Experimental conditions were sufficiently well known to allow for good model-measurement comparison, and the result qualitatively supported the 
hypotheses discussed in Section 2, but there were some quantitative differences between model and measurement due to experimental complications involving the shape of the cloud and interaction with the bubble generator itself. These complications where eventually worked out through the use of a confined bubble cloud, where the shape was well-known, [17] and using an indoor tank facility, where free-field scattering from the artificial bubble cloud could be achieved. [18] Bill's hypothesis has now been accepted in the community, and model clouds indeed behave as effective fluid objects with acoustic properties given by Wood's equation.
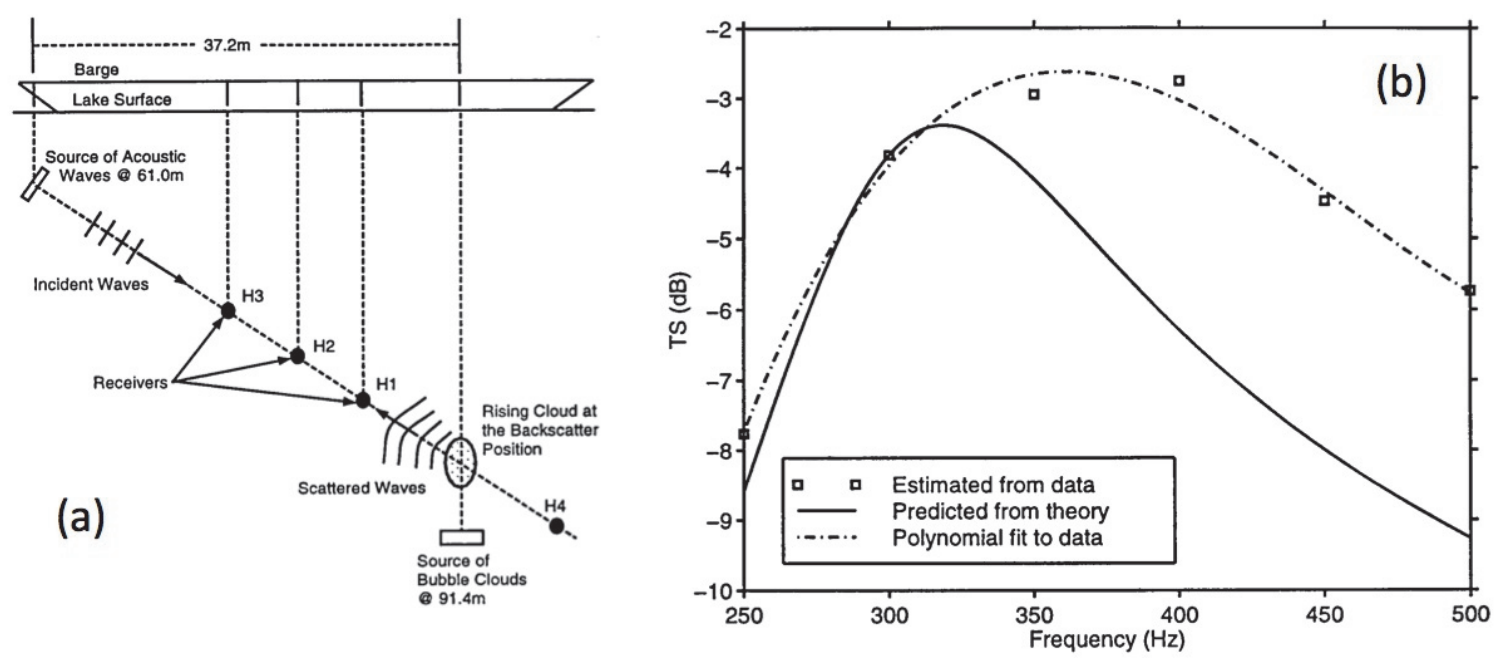

Fig.2: (a) Experimental apparatus used in the Lake Seneca experiment to examine scattering from bubble clouds. (b) Measurement results compared to a model of fluid sphere scattering using Wood's equation to describe the acoustic properties of the cloud. Figures adapted from Ref. [16].

\section{PROPAGATION IN BUBBLY LIQUIDS AND GAS-BEARING SEDIMENTS}

At the time, there was also substantial interest within the community in sound propagation in bubbly liquids at frequencies beyond the "Wood's limit," that is, at frequencies near and beyond the resonance frequencies of the individual bubbles in the mixture. Also of interest was sound transmission in high void fraction mixtures. Such conditions exist early in the life of an oceanic bubble cloud, and measurement is complicated by the predicted excessive attenuation coefficients. Commander and Prosperetti [19] had published a new rigorous propagation model in 1989 but had not found agreement between their model and measurements available at the time, which even in 1989, were already decades old. Bill and colleagues set out to measure bubbly liquid sound speed and attenuation using an impedance tube method, which eventually was successful [20] and proved that for most oceanic void fractions the model of Ref. [19] was sufficient to describe attenuation, even at the individual bubble resonance frequency (IBRF). The apparatus and typical data are shown in Fig. 3.

Interest shifted to the acoustics of gas-bearing sediments and of mud, and since the complexity of this medium is comparatively high, Bill's focus shifted back to the low frequency regime and he investigated the use of Wood's equation to describe gas-bearing mud. It was found that in fluid-like muds that contain bubbles, a very simple equation, 
derived from Wood's equation, describes the measured sonic velocity, which depends only on the void fraction, the sediment bulk density, and the local hydrostatic pressure. This is somewhat remarkable, because dozens of parameters are required to fully describe the details of a gas bearing sediment, including the fluid and sediment grain parameters and their packing, plus the bubble size distribution and air properties. Again, an acoustic resonator technique was used to measure the sound speed in a gas-bearing mud. X-ray micro-computed tomography was used to determine the void fraction, and with knowledge of the sediment effective density (measured directly) the measured sound speed agreed exactly with the prediction of the three-parameter model.

(a)

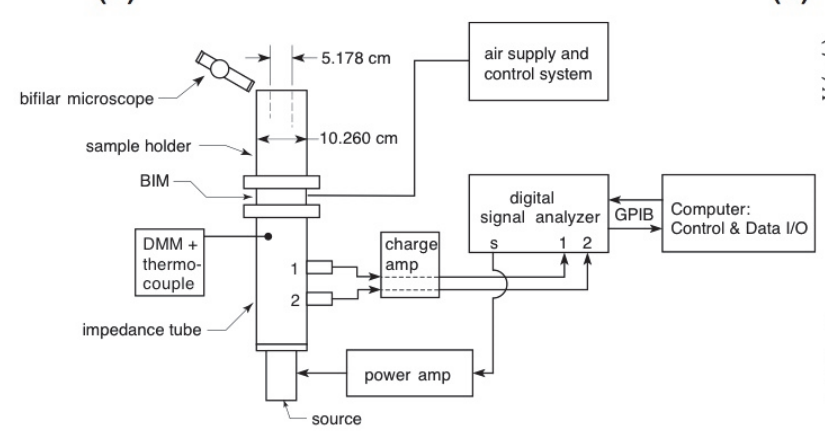

(b)
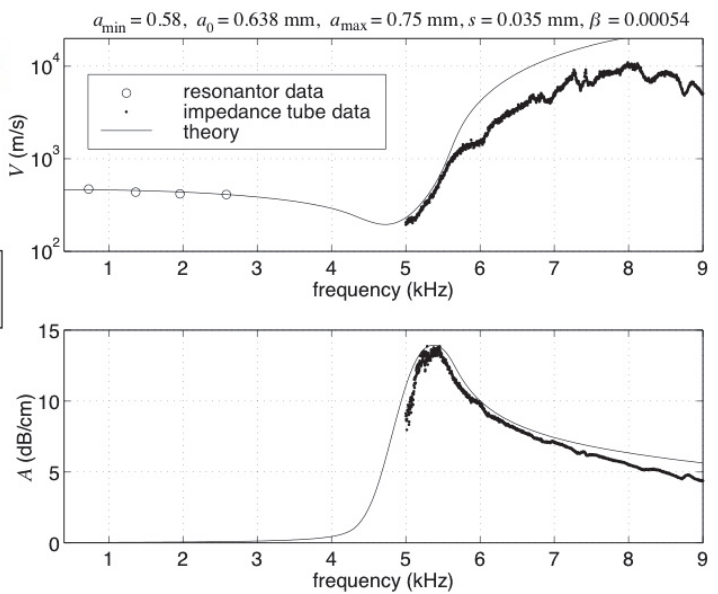

Fig.3: (a) Water-filled impedance tube apparatus used to measure the sound speed and attenuation in bubbly liquids at and near the individual bubble resonance frequency (IBRF). (b) Comparison between measurements and the model of Ref. [19]. Note that IBRF is near $5.2 \mathrm{kHz}$ and the attenuation is about $140 \mathrm{~dB}$ per meter. Figures adapted from Ref. [20].

\section{REINTRODUCTION OF MALLOCK TO THE MALLOCK-WOOD EQUATION}

Sometime circa late 1990s, online booksellers proliferated and made the locating and purchasing of old books both inexpensive and easy. Bill purchased an original edition of Wood's A Textbook of Sound (1930), and found that it differed from the later (1950's) edition he had been using. Specifically, in the section that describes what came to be known as Wood's equation, there was a reference to an earlier work by Mallock [21] on the acoustics of bubbly liquids, that was absent from the later editions. Bill tracked down Mallock's paper and found that Mallock had actually derived an equivalent form of Wood's equation in 1910, which was twenty years before Wood published it himself. Once Bill discovered Mallock, he began referring to Wood's equation as the MallockWood equation, in an effort to give back some of the credit to Mallock, whose contribution had somehow been overlooked.

It is interesting to speculate as to how this might have occurred. Bill hypothesized colloquially that it was because Mallock had incorrectly plotted the equation in the 1910 paper. Mallock's plot is shown in Fig. 4(a) and a number of things look unusual to a modern reader. First, the abscissa is reversed from modern convention. Second, and most importantly, the shape of the plot is unfamiliar, but the limiting high and low volume 
fraction sound speeds do assume the values for air and water respectively, as we expect. Even with the reversed abscissa, we expect a smooth curve, like that shown in Fig. 4(c), rather than the three-sectioned curve of Mallock. It is easy for a modern reader to assume Mallock's plot was either a sketch or just incorrect given the tools of his time. Upon further inspection (which took this author (PSW) ten more years to understand), Mallock's original plot is actually plotted on three different concatenated abscissas, from 0 to 1 on a linear scale, then from 1 to 1000 , then from 1000 to 1000000 . This can of course also be done with a modern plot as in Fig. 4(b), and one finds that Mallock's plot was actually quite accurate after all. We can only speculate as to how this would have modified Bill's opinion of why Mallock was lost to history, but it does seem to refute the contention that Mallock was overlooked because of an inaccurate plot.
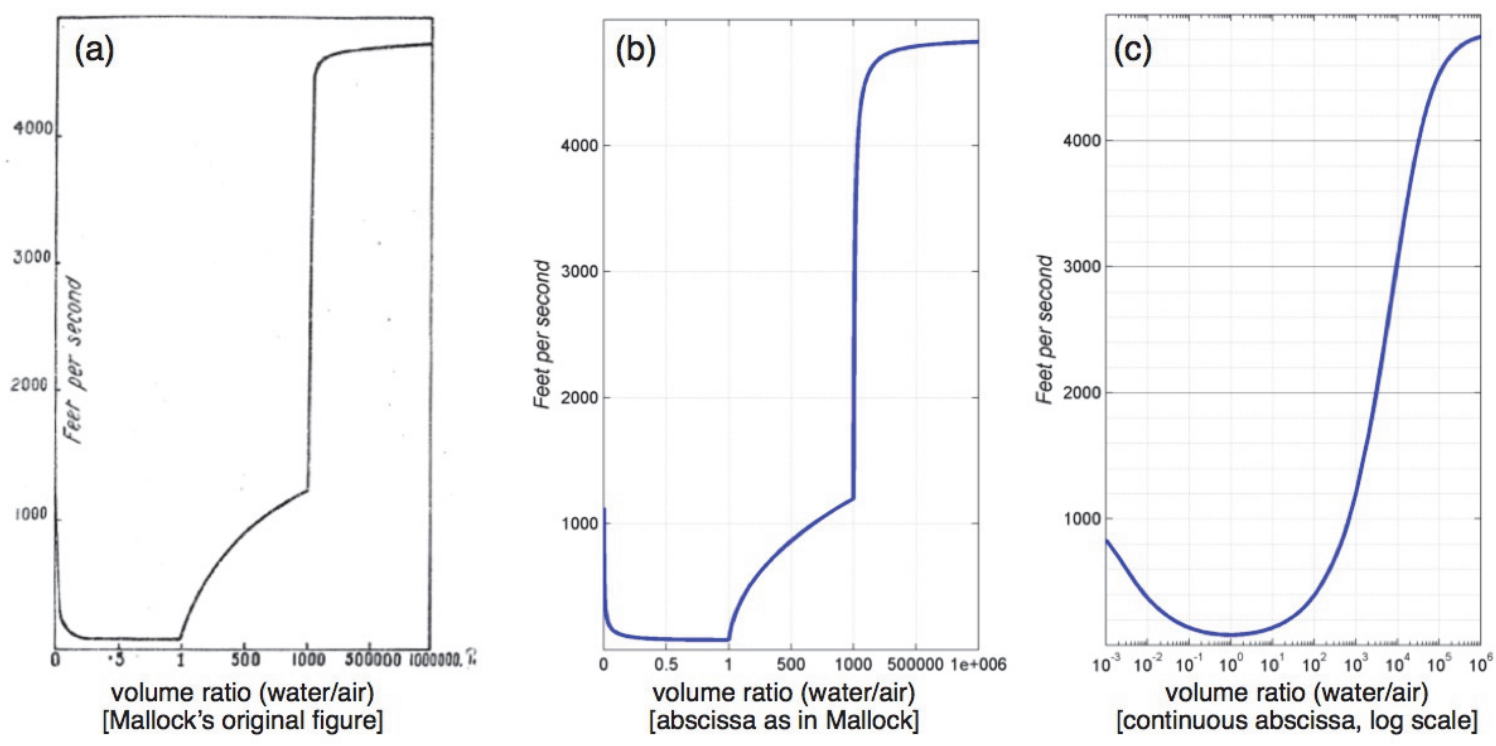

Fig.4: (a) Mallock's original 1910 plot of sound speed in bubbly water, as it appeared with a three-segment abscissa. [21] Modern versions of the same plot are shown with the same threesegment abscissa (b) and in a more familiar form (c) with a continuous abscissa.

\section{SUMMARY}

Bill Carey was trained as a nuclear physicist but almost immediately started to think in terms of underwater acoustics and the acoustics of bubbles. He soon transitioned into underwater acoustics and remained in that field for the rest of his career. He discovered Wood's equation while working on nuclear reactor technology and carried it into his underwater acoustics career. Over the next thirty years, Bill used Wood's equation to describe the sound radiated by bubble clouds that are generated by wind-driven breaking waves, to describe acoustic scattering from bubble clouds, and to describe acoustic propagation through bubble clouds and gas-bearing sediments. In the last several years of his career, Bill discovered that Mallock was the originator of what had previously been referred to as Wood's equation and began a campaign to reestablish Mallock's contribution. Bill began referring to the equation as the Mallock-Wood equation, rather than just Wood's equation. One of Bill's uncompleted quests, to discover the cause of the 
historical oversight, has been brought one step closer to completion. It had been suggested that Mallock was not remembered for his equation because he had published an incorrect plot in 1910. We now see that the 1910 plot was in fact quite accurate. We hope this work helps to carry on Bill's campaign to restore Mallock's legacy as a progenitor of the Mallock-Wood equation.

\section{ACKNOWLEDGEMENTS}

This work was supported by the Office of Naval Research Ocean Acoustics program. The authors are grateful for their time with Bill Carey and acknowledge his in spirit contribution to this work. Craig N. Dolder is acknowledged for his discovery of Mallock's three-segmented abscissa, and for contribution of the plots in Fig. 4.

\section{REFERENCES}

[1] W.M. Carey, "A Theoretical Evaluation of Ultrasonic Detection of Small Gas Bubbles," Naval Medical Research Institute, Bethesda, MD; DTIC Accession Number: AD0784369, 1972.

[2] W.D. Ulrich and W.M. Carey, "A Range-Gated Pulse-Echo Ultrasonic System for Detection of Bubbles in Decompression Sickness," Naval Medical Research Institute, Bethesda, MD; DTIC Accession Number: AD0787493, 1974.

[3] W.M. Carey, "Acoustic detection of the collapse of a sodium vapor bubble in an infinite sea of sodium," Argonne National Laboratory Technical Memorandum ANL-CT-76-21, 1975.

[4] W.M. Carey, T.T. Anderson, and J.P. Bobis, "The acoustic detection of boiling in the sodium loop safety facility in-reactor experiment P1," Argonne National Laboratory Technical Meomrandum ANL-CT-76-33, 1976.

[5] H.B. Karplus, "The velocity of sound in a liquid containing gas bubbles," Armour Research Foundation of Illinois Institute of Technology C00-248, June 11, 1958.

[6] W.M. Carey and M.P. Bradley, "Low-frequency ocean surface noise sources (A)," J. Acoust. Soc. Am. 78, p. S1 (1985).

[7] A. Prosperetti, "Bubble-related ambient noise in the ocean (A)," J. Acoust. Soc. Am. 78, p. S2 (1985).

[8] A.B. Wood, A Textbook of Sound, 1st ed. New York: MacMillan, 1930.

[9] R.A. Roy, W.M. Carey, M. Nicholas, J.A. Schindall, and L.A. Crum, "Lowfrequency scattering from submerged bubble clouds," J. Acoust. Soc. Am. 92, 2993-2996 (1992).

[10] W.M. Carey and D. Browning, "Low frequency ocean ambient noise: Measurements and theory," in Sea Surface Sound, B. R. Kerman, Ed. Boston: Kluwer, 1988, pp. 361-376.

[11] W.M. Carey and J.W. Fitzgerald, "Low frequency noise from breaking waves," in Natural Physical Sources of Underwater Sound, B. R. Kerman, Ed. Boston: Kluwer, 1993, pp. 277-304.

[12] W.M. Carey, J.W. Fitzgerald, E.C. Monahan, and Q. Wang, "Measurement of the sound produced by a tipping trough with fresh and salt water," J. Acoust. Soc. Am. 93, 3178-3192 (1993). 
[13] W.M. Carey and R.A. Roy, "Sound scattering from microbubble distributions near the sea surface," in Ocean Reverberation, D. D. Ellis, J. R. Preston, and H. G. Urban, Eds. Dordrecht, Netherlands: Kluwer Academic, 1993, pp. 25-44.

[14] W.M. Carey and R.A. Roy, "The low-frequency radiation and scattering of sound from bubbly mixtures near the sea surface," in Proceedings of the Second European Conference on Underwater Acoustics, Vol. 1, L. Bjørnø, Ed., Luxembourg: European Commission, 1994, pp. 207-212.

[15] W.M. Carey, J. Fitzgerald et. al., "Measurement of the sound produced by a tipping trough with fresh and salt water," J. Acoust. Soc. Am. 93, 3178-3192 (1993).

[16] A.D. Gephart, "Acoustic scattering from compact bubble clouds," M.S. Thesis Boston University, 1999.

[17] P.S. Wilson, R.A. Roy, and W.M. Carey, "Acoustic scattering from a bubblyliquid-filled compliant cylinder," Acoustics Research Letters Online 2, 103-108 (2001).

[18] T.R. Hahn, T.K. Berger, and M.J. Buckingham, "Acoustic resonances in the bubble plume formed by a plunging water jet," Proc. R. Soc. Lond. A 459, 17511782 (2003).

[19] K.W. Commander and A. Prosperetti, "Linear pressure waves in bubbly liquids: Comparison between theory and experiments," J. Acoust. Soc. Am. 85, 732-746 (1989).

[20] P.S. Wilson, R.A. Roy, and W.M. Carey, "Phase speed and attenuation in bubbly liquids inferred from impedance measurements near the individual bubble resonance frequency," J. Acoust. Soc. Am. 117, 1895-1910 (2005).

[21] A. Mallock, "The damping of sound by frothy liquids," Proc. R. Soc. Lond. A 84, 391-395 (1910). 